\title{
Resiliência e Vulnerabilidade no Cuidado com o Idoso Dependente: Um Estudo de Caso
}

\author{
Lara Monteiro Schuck ${ }^{1}$ \\ Residência em Serviço de Saúde Comunitária - Saúde da Família e Comunidade do Grupo \\ Hospitalar Conceição, Porto Alegre, Rio Grande do Sul, Brasil
}

Clarissa De Antoni

Departamento de Psicologia da Universidade Federal de Ciências da Saúde de Porto Alegre, Porto Alegre, Rio Grande do Sul, Brasil

\begin{abstract}
Resumo
O envelhecimento da população brasileira e o desenvolvimento de doenças crônicas em idosos colocam em questão o papel do cuidador familiar, o qual tem sido visto, atualmente, como um novo papel social. O objetivo deste estudo foi investigar, através de um estudo de caso com uma família que tinha sob seus cuidados um membro idoso dependente, a relação entre cuidador e idoso a partir da perspectiva da Teoria Bioecológica do Desenvolvimento Humano (TBDH) e da Psicologia Positiva, com foco no microssistema e nas relações entre cuidador e idoso. Os instrumentos utilizados foram uma entrevista semiestruturada, a Entrevista Familiar Estruturada, o Inventário de Percepção do Suporte Familiar, uma observação naturalística, um genograma e uma pesquisa documental no prontuário familiar. Foram identificados como fatores de risco os sentimentos de solidão e inutilidade do idoso, a sobrecarga e o estresse da cuidadora e a falta de apoio social formal e informal para esta família. Os fatores de proteção encontrados foram a positividade e a crença religiosa do idoso, a ajuda de outros parentes no cuidado e a presença de uma equipe de saúde que prestava cuidados domiciliares. Percebe-se que a família encontra-se em processo de resiliência, apesar da presença de fatores de risco significativos.
\end{abstract}

Palavras-chave: Idoso, cuidadores familiares, resiliência, família.

\section{Resilience and Vulnerability in Care for the Elderly Dependent: A Case Study}

\begin{abstract}
The aging of the population and the development of chronic diseases in the elderly rase questions about the role of the family caregiver, which has been seen currently as a new social role. The aim of this study was to investigate, through a case study of a family who had under his care a dependent elderly member, the relationship between the caregiver and elderly from the perspective of the bioecological theory of human development (TBDH) and Positive Psychology, focusing on microsystem and the relationships between caregiver and elderly. The instruments used were one semi-structured interview, the Structured Family Interview, the Inventory of Perceived Family Support, a naturalistic observation, a genogram
\end{abstract}

1 Endereço para correspondência: Universidade Federal de Ciências da Saúde de Porto Alegre, Rua Sarmento Leite, 245, sala 207, Centro, Porto Alegre, RS, Brasil 90050-170. E-mail: s.mlara@hotmail.com e clarissadeantoni@yahoo.com.br

Agradecemos ao Grupo Hospitalar Conceição (GHC) pelo apoio institucional e à família participante pela disponibilidade e colaboração. 
and documentary research in family records. Were identified as risk factors feelings of loneliness and uselessness of the elderly, burden and stress of caregiving and lack of formal and informal social support for this family. As protective factors, were found positivity and religious faith of the elderly, help in the care from other relatives and the presence of a health care team which paid home care. One realizes that the family is in the process of resilience, despite the presence of significant risk factors.

Keywords: Aged, caregivers, resilience, family.

\section{Resiliencia y Vulnerabilidad en el Cuidado de Personas Mayores Dependientes: Un Estudio de Caso}

\section{Resumen}

El envejecimiento de la población y el desarrollo de enfermedades crónicas en los ancianos en tela de juicio el papel del cuidador familiar, que se ha visto en la actualidad como un nuevo rol social. El objetivo de este estudio fue investigar, a través de un estudio de caso de una familia que tenía bajo su cuidado un miembro mayor dependiente, la relación entre el cuidador y ancianos desde la perspectiva de la teoría bioecológica de desarrollo humano (TBDH) y la Psicología Positiva, centrándose en el microsistema y en las relaciones entre el cuidador y ancianos. Los instrumentos utilizados fueron una entrevista semi-estructurada, la Entrevista Estructurada Familiar, el Inventario de Percepción de Apoyo a la Familia, una observación naturalista, un genograma y la investigación documental en los archivos familiares. Se identificaron como factores de riesgo de los sentimientos de soledad e inutilidad de los mayores, la carga y el estrés del cuidado y la falta de apoyo social formal e informal para esta familia. Se encontraron factores de protección positividad y la fe religiosa de las personas mayores, ayuda en el cuidado de otros familiares y la presencia de un equipo de atención médica que pagó la atención domiciliaria. Uno se da cuenta de que la familia está en el proceso de resiliencia, a pesar de la presencia de factores de riesgo significativos.

Palabras clave: Anciano, cuidadores familiares, resiliencia, família.

Uma tendência crescente nos países em desenvolvimento é o envelhecimento de sua população. Segundo censo realizado pelo Instituto Brasileiro de Geografia e Estatística (IBGE, 2011), a população acima de 60 anos no Brasil representa $10,8 \%$ da população total e mostra um crescimento em relação ao censo anterior - realizado em 2000 - quando esta população representava 8,5\%. Estes dados apontam, além do crescimento desta população no país, que a qualidade de vida dos idosos deve ser objeto de atenção, visto que a tendência é o aumento gradativo destes números (Caldas, 2003; Lavinsky \& Vieira, 2004; Moreira \& Caldas, 2007; Nardi $\&$ Oliveira, 2008; Tier et al., 2006). Com a longevidade avançando, a probabilidade de se ter idosos com doenças crônicas é cada vez maior (Caldas, 2003; Lavinsky \& Vieira, 2004; Mazza \& Lefévre, 2005), sendo que, no Brasil, quem assume os cuidados destes idosos, em sua maioria, são seus familiares (Caldas, 2003; Karsch, 2003; Moreira \& Caldas, 2007; Willig, Lenardt, \& Méier, 2012). Algumas tendências da família atual, como o número cada vez menor de filhos, e o fato de que geralmente a maioria dos membros trabalha fora de casa e contribui economicamente para a renda familiar (Augusto, da Silva, \& Ventura, 2009), podem impactar a provisão de cuidados destes idosos.

Segundo Augusto et al. (2009), o processo de cuidado familiar sempre existiu. Entretanto, esse papel só tem sido legitimado como tal mais recentemente. Assumir o cuidado de um membro idoso, que até então era independente, pode suscitar inúmeros sentimentos paradoxais nas famílias, que envolvem tanto retribuição e gratidão quanto angústia, dúvidas, raiva, entre outros (Augusto et al., 2009; Caldas, 2003; Lavinsky 
\& Vieira, 2004; Mazza \& Lefévre, 2005; Sebastião \& Albuquerque, 2011; Silveira, Caldas, \& Féres-Carneiro, 2006). Esta situação exige uma readaptação social, financeira e da própria dinâmica familiar, e são colocadas em voga questões como o despreparo técnico e emocional frente ao manejo da dependência do idoso, e o resgate de questões relacionais entre os membros, o que pode dificultar a provisão de cuidados adequados ao idoso.

Estudos apontam, como consequência do ato de cuidar destes membros, a efetivação de mudanças no cotidiano pessoal, profissional e familiar, tendo o cuidador, muitas vezes, que abdicar de seus projetos de vida em função do manejo deste idoso (Thober, Creutzberg, \& Viegas 2005). Por outro lado, Cruz, Loureiro, Fernandes e Silva (2010) apontam aspectos positivos percebidos por familiares que se tornaram cuidadores, dentre eles uma mudança de postura em relação à vida, enxergando-a de maneira mais flexível. Citam também o fortalecimento da capacidade pessoal frente às adversidades, os quais podem ser vistos como fatores que auxiliam estes familiares a desempenhar esta tarefa de maneira mais adequada.

Através do olhar direcionado aos atores sociais envolvidos, pode-se problematizar a forma como as políticas públicas destinam o cuidado dos idosos dependentes à família. A partir destas questões, esse estudo teve como objetivo estudar a relação entre cuidador e idoso a partir da perspectiva da Teoria Bioecológica do Desenvolvimento Humano (TBDH) e da Psicologia Positiva, com foco no microssistema familiar.

\section{A Compreensão da Relação Cuidador e Idoso a Partir da Teoria Bioecológica do Desenvolvimento Humano (TBDH)}

A TBDH (Bronfenbrenner, 1979/1996) permite a análise dos fatores que influenciam, de alguma forma, o desenvolvimento humano, privilegiando o desenvolvimento no contexto, e levando em conta diferentes dimensões interrelacionadas: a Pessoa, o Processo, o Contexto e o Tempo (PPCT). A dimensão Pessoa envolve as características biopsicossociais de cada sujeito analisado; a dimensão Processo diz respeito às interpretações sobre as interações estabelecidas nos ambientes; já o Contexto compreende a interação de quatro níveis ambientais; e a dimensão Tempo, é formada por eventos sociais, históricos e cotidianos ao longo da vida da pessoa (Bronfenbrenner, 1979/1996, 2011). No Contexto, encontramos o microssistema familiar, que corresponde ao ambiente familiar e suas interações; o mesossistema, que corresponde às trocas que a família realiza com outros microssistemas, como serviços de saúde, escolas, local de trabalho etc.; o exossistema, que corresponde às políticas $\mathrm{e}$ programas que interferem indiretamente no microssistema familiar e nas ações dos membros; e o macrossistema, que envolve padrões culturais e crenças da sociedade em que a família vive, os quais perpassam todos os outros sistemas. Em todos os contextos em que vive o Eu Ecológico (ser humano ou grupo familiar em desenvolvimento) há fatores de risco e de proteção ativos, funcionando de maneira dinâmica e influenciando os processos familiares em seu desenvolvimento. Segundo De Antoni e Koller (2010), o termo "risco" tem sido utilizado para denominar fatores ou situações potencialmente estressoras, que possam predispor a um desfecho negativo ou indesejado; já o termo "proteção" refere-se a fatores que poderão defender ou fortalecer a pessoa frente a uma situação de vulnerabilidade.

Desta forma, os fatores de risco e de proteção são processos, e não eventos estáticos, e devem ser compreendidos de acordo com a situação e o contexto, pois, dependendo das suas implicações nas relações e os resultados específicos de cada situação, alguns indicadores podem constituir-se tanto como risco quanto como proteção (De Antoni \& Koller, 2010). A resiliência, portanto, refere-se a processos que operam na presença do risco para produção de características saudáveis (Morais \& Koller, 2004). Já a vulnerabilidade tem sido relacionada com características inatas ou adquiridas através das relações que o indivíduo estabelece nos diferentes contextos, que dificultam o desenvolvimento de respostas adaptativas a situações de crise quando estas ocorrem (Cecconello, 2003). 
Diferentes fatores interagem entre si e modificam o percurso do sujeito, tanto para produção de experiências estressoras quanto para experiências protetoras (Cassol \& De Antoni, 2011; Poletto \& Koller, 2011), ou seja, devem-se levar em consideração os desafios enfrentados e os recursos de cada membro familiar, bem como do grupo familiar como uma unidade (De Antoni, Barone, \& Koller, 2011). Segundo a conceituação de resiliência como um processo, esta seria um fenômeno complexo que se constrói na inter-relação entre os múltiplos contextos com os quais o ser humano ou o microssistema familiar interage de maneira direta ou indireta (Silva, Lacharité, Silva, Lunardi, \& Lunardi, 2009). Ao se considerar, portanto, os processos de resiliência de um microssistema familiar, deve-se voltar o olhar ao processo interacional que se dá neste grupo, ao longo do tempo, e que fortalece tanto a família quanto seus indivíduos (Silva et al., 2009). Isto é importante para que a família possa se reorganizar após enfrentar períodos críticos, produzindo processos entre seus membros que gerem competência e não disfunção (Cecconello, 2003).

\section{Método}

Trata-se de um estudo de caso exploratório, qualitativo e transversal. O caso descrito neste estudo foi selecionado por conveniência, sendo a família selecionada com base em alguns critérios: ter um idoso dependente fisicamente, mas com a cognição preservada, para que pudesse responder aos instrumentos; ter um familiar como cuidador principal; estar cadastrada na Unidade Básica de Saúde do território onde vivia.

Após o contato e consentimento dos familiares, realizaram-se visitas sistemáticas, nas quais se aplicou os seguintes instrumentos no idoso e em sua cuidadora: uma entrevista semiestruturada (que buscou investigar a situação de cuidado e os sentimentos gerados por ela), adaptada para cada um dos participantes e elaborada pelas pesquisadoras; a Entrevista Familiar Estruturada (EFE; Féres-Carneiro, 1997), que investiga dimensões relativas a comunicação, regras, papéis, liderança, manifestações de agressividade, afeição física, interação conjugal, individualização, integração, autoestima e saúde emocional (Teodoro, 2012); e o Inventário de Percepção do Suporte Familiar (IPSF; Baptista, 2007), respondido apenas pela cuidadora, que investiga três características do suporte familiar, intituladas Afetivo - Consistente, Adaptação Familiar e Autonomia (Teodoro, 2012). Foi realizada, ainda, uma observação naturalística (inserção ecológica) do contexto familiar e o estudo do genograma. Com o objetivo de realizar um olhar ampliado sobre a situação, foi realizada, ainda, uma pesquisa documental no prontuário familiar, para busca de dados de saúde e características do acompanhamento familiar.

\section{Participantes}

A família participante apresentava em sua configuração um idoso que necessitava de cuidados sistemáticos por ter um grau elevado de dependência física, em decorrência de Acidente Vascular Cerebral (AVC). A filha era a cuidadora principal, o que corrobora a tendência exposta na literatura (Pereira, Santos, Fhon, Marques, \& Rodrigues, 2013). Para fins de preservar a identidade dos participantes e manter a análise dos membros familiares de acordo com seus papéis no microssistema, utilizou-se, para apresentação, a letra inicial do seu papel em relação ao idoso: I (Idoso); F (Filha); E (Esposa); G (Genro); N1 (Neto 1); N2 (Neto 2).

\section{Análise dos Dados}

O Modelo para análise dos dados utilizado nesse estudo foi proposto por Koller e De Antoni (2004), no qual são apresentados os fatores de risco e de proteção nos diferentes contextos ecológicos. Essa análise ocorreu a partir da triangulação dos dados coletados pelos instrumentos utilizados, relacionando-os com a literatura disponível sobre a temática. Foram identificados indicadores de risco e de proteção que perpassavam os diferentes sistemas em que seus membros se inseriam. Estes indicadores 
relacionavam-se à situação de dependência, podendo configurar-se de risco quando dificultavam, em algum nível, a provisão de cuidados adequados ao idoso, bem como a própria resiliência familiar diante da situação. Poderiam, ainda, configurarem-se fatores protetivos quando, ao contrário, facilitavam a provisão de cuidados adequados ao idoso, bem como contribuíam para a manutenção da saúde física e emocional dos membros familiares, tornando-os mais resilientes frente a esta situação. Estes indicadores não são estáticos, podendo ora ser considerados de risco, ora de proteção, dependendo das variáveis associadas. Portanto, a resiliência foi conceituada no presente estudo como um processo (Morais \& Koller, 2004), aprofundando-se sua análise nos processos de resiliência/vulnerabilidade familiar, com base nos "Processos-chave da Resiliência" (Walsh, 1998), o qual sistematiza a análise dos processos no contexto familiar. De maneira mais superficial, investigaram-se os processos de resiliência/vulnerabilidade individuais da cuidadora e do idoso.
Por estarem interligados e em relação, os indicadores de proteção e de risco foram analisados dinamicamente. Estes indicadores também foram agrupados em fatores de análise que emergiram das entrevistas e instrumentos utilizados. Tais fatores foram analisados de acordo com o que concerne aos sistemas: eu ecológico do idoso, eu ecológico da cuidadora e microssistema familiar, em relação à História Anterior (fator que se refere aos acontecimentos e relações prévias ao AVC), ao Cuidado (fator que se refere à prática de cuidado familiar em relação ao idoso), à Autopercepção (refere-se a como os membros familiares, bem como a família como uma unidade, percebem-se), à Positividade (refere-se aos sentimentos de positividade, otimismo, esperança, fé etc. presentes/ ausentes na família e em seus membros) e às Relações Intrafamiliares (refere-se às relações estabelecidas entre os membros da família). Esses fatores foram integrados ao modelo Pessoa-Processo-Contexto-Tempo (PPCT) da TBDH, para uma compreensão dinâmica e ecológica do fenômeno e dos fatores de risco e de proteção presentes.

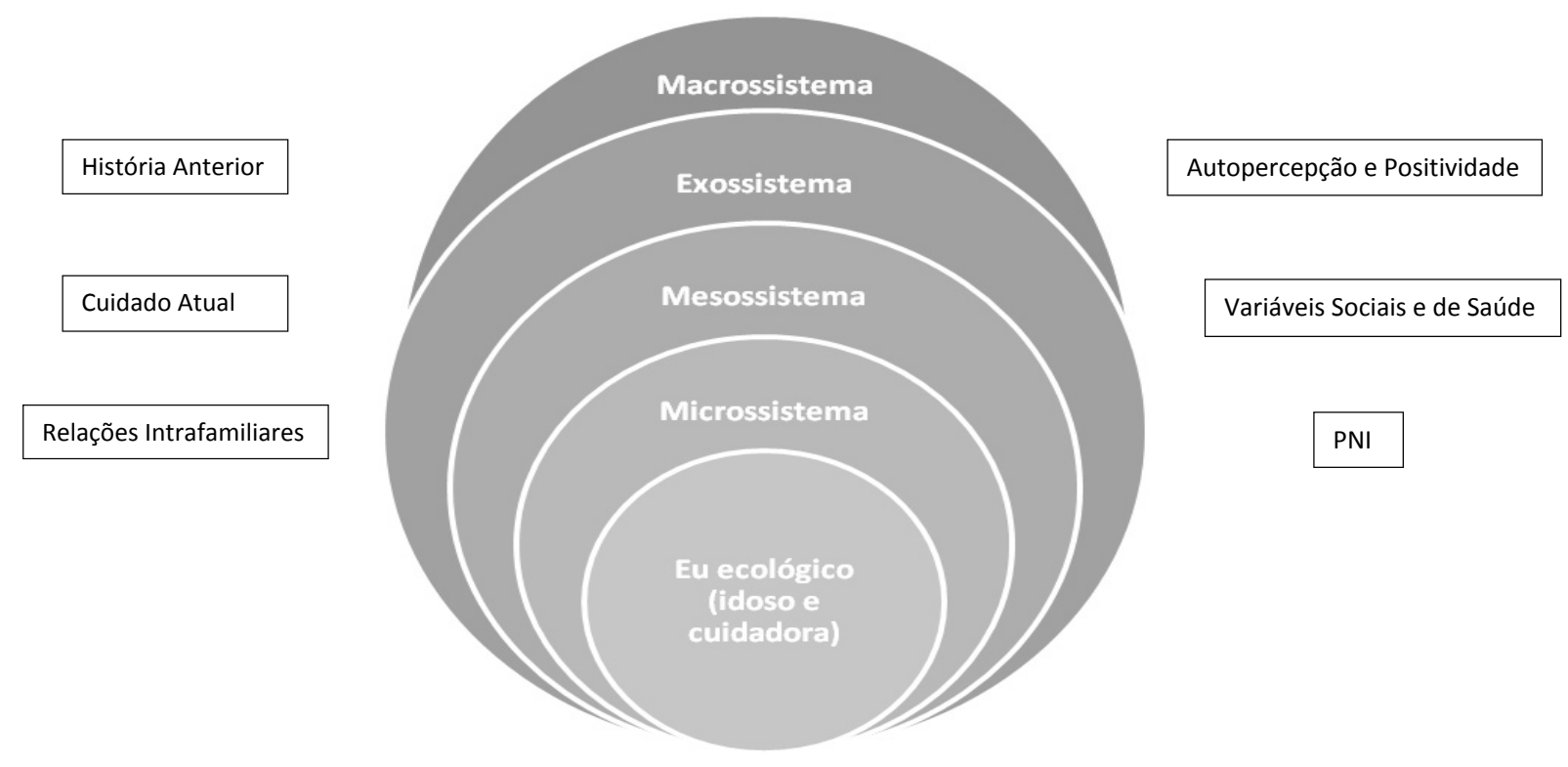

Figura 1. Modelo de análise dos dados.

Este estudo seguiu todas as recomendações éticas para a realização de pesquisas com seres humanos, de acordo com as orientações da Resolução 196/1996 do Conselho Nacional de Saúde. Todos os participantes assinaram Termo de
Consentimento Livre e Esclarecido (TCLE) e o presente estudo obteve aprovação do Comitê de Ética em Pesquisa da Universidade Federal de Ciências da Saúde de Porto Alegre, sob protocolo ${ }^{\circ}$ 08429712.4.0000.5345. 


\section{Resultados e Discussão}

\section{Caracterização e Breve Histórico da Família}

A família era formada pelo idoso, I (61 anos), sua esposa, E (63 anos), sua filha, F (26 anos) - a cuidadora familiar principal - seu marido, $\mathbf{G}$ (26 anos), e seus dois filhos, N1 (11 anos) e N2 (1 ano). $\mathbf{F}$ foi adotada pelo casal quando tinha três dias de vida. O idoso tinha Hipertensão e Dia- betes prévia aos Acidentes Vasculares Cerebrais (AVCs) e, atualmente, aparentava fragilidade física devido aos episódios sofridos em 2010; no entanto, não aparentava estar com o peso abaixo do esperado. O apartamento da família estava sempre bastante bagunçado, tornando difícil o trânsito livre das pessoas, pois sempre havia objetos no chão ou empilhados: "Olha, é um pra arrumar e dez pra fazer bagunça!" (F). A Figura 2 apresenta o Genograma familiar.

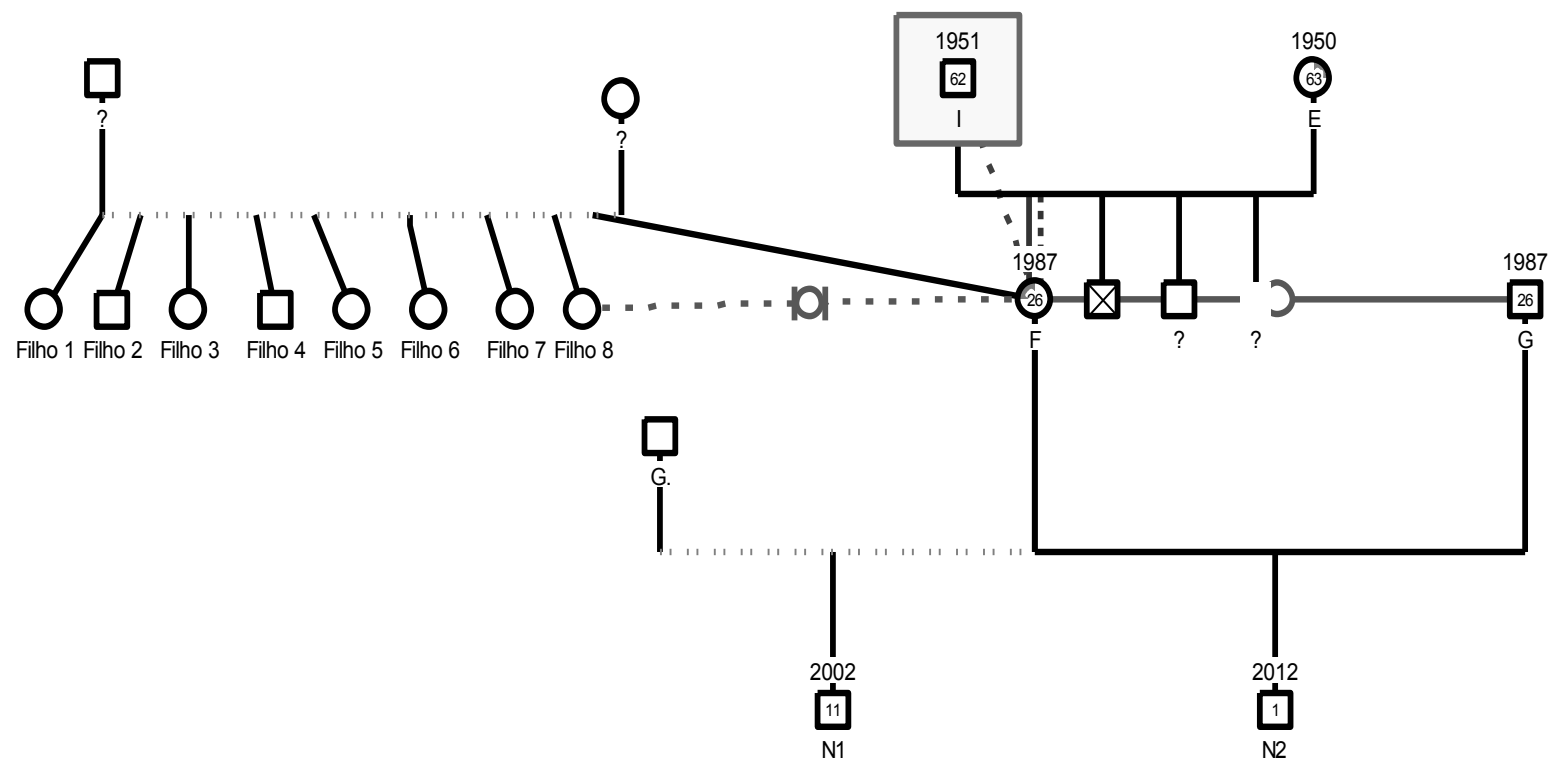

Nota. Legenda:

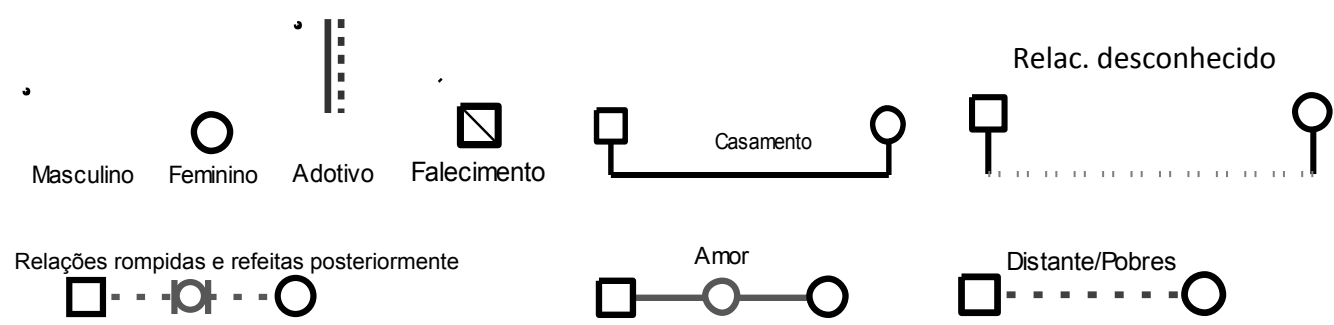

Figura 21. Genograma da família.

Moram na casa I, E e N1, o qual não é filho de G. Os demais familiares frequentam diariamente a casa de $\mathbf{I}$, e $\mathbf{F}$ é quem fica responsável por todos os cuidados do pai, até a chegada de sua mãe em casa, à noite. Em noites alternadas, F dorme no apartamento, auxiliando a mãe nos cuidados. $\mathbf{E}$ trabalha como doméstica e $\mathbf{F}$ parou de trabalhar e de estudar em função do AVC do pai, ficando responsável integralmente pelos cuidados com o pai e com a casa. Seu marido trabalha em noites alternadas, e N1 frequenta a escola. Em 2010, I trabalhava em uma Associação de Trabalhadores, quando teve o primeiro AVC, e foi levado até o hospital, onde sofreu outros dois 
AVCs que o incapacitaram fisicamente, ficando com hemiparesia do lado esquerdo. Devido ao agravamento do quadro, $\mathbf{F}$ teve que abandonar a faculdade e seu trabalho, e, juntamente com seu marido, passou a cuidar do seu pai. Desde a ocorrência do primeiro AVC, a equipe de saúde da Unidade Básica de Saúde (UBS) passou a acompanhar com frequência a situação da família, principalmente do idoso. Em outubro daquele ano, I teve que retornar ao hospital para amputação do pé esquerdo. A família foi incluída no Programa de Atendimento Domiciliar (PAD) estratégia de desospitalização do Sistema Único de Saúde (SUS) e referenciamento dos cuidados para a Atenção Primária à Saúde - , e a equipe passou a realizar as consultas, portanto, no domicílio da família.

\section{Indicadores de Proteção e de Risco}

Diversos indicadores de proteção e de risco foram encontrados para análise dos processos de resiliência e vulnerabilidade no microssistema familiar. Estes indicadores poderiam potencializar a resiliência ou a vulnerabilidade frente à situação de dependência.

\section{História Anterior}

Em relação aos indicadores de proteção, pode-se destacar a vida ativa que mantinham os familiares: I trabalhava - fora e dentro de casa - assim como sua esposa e sua filha. $\mathbf{F}$ já era independente financeiramente, cursava ensino superior, morava sozinha, tinha um companheiro e um filho, o que indica que esta era uma família que permitia movimentos de independência dos seus membros. Por outro lado, havia previamente uma relação familiar distante, com pouca afetividade, além de dificuldades de expressão de sentimentos e emoções e pouco diálogo entre os membros. Ainda, pela própria imprevisibilidade do AVC, a família não teve como preparar-se previamente (C. P. B. Vieira \& Fialho, 2010). Além disso, as mudanças na configuração familiar brasileira resultam na falta de cuidadores familiares para os idosos que ficarão dependentes e/ ou acamados (Tavares, Scalco, Vieira, Silva, \& Bastos, 2012).

\section{Cuidado}

Com relação a esta situação de cuidado familiar que se configurou após a ocorrência dos AVCs, destacam-se como indicadores protetivos a ausência de sequelas cognitivas graves em I, o que permite alguma independência, como sentar-se/ deitar-se sozinho e fazer as refeições sem necessitar de muito auxílio, além de poder comunicar-se de maneira direta com a cuidadora e seus familiares. $\mathrm{O}$ idoso se sente bem cuidado pela filha: "Melhor é impossivel" (I). Os remédios estão bem organizados, I toma suas medicações corretamente, e a família sabe responder com propriedade às questões sobre a saúde dele.

Outros indicadores protetivos são a possibilidade de eventual distanciamento da situação de cuidado que a cuidadora pode estabelecer, por não morar no mesmo apartamento, e o recebimento de apoio emocional e cognitivo do marido (Pereira et al., 2013; C. P. B. Vieira \& Fialho, 2010), segundo relata:

Porque pra mim, assim, quando eu tenho que chorar, quando eu tenho que falar alguma coisa, eu converso com o $\boldsymbol{G}$, ele me ajuda um monte. ... É tudo ele, porque quando eu to estressada, ele até já sabe assim... Ele já, ele já me entende. (F)

A cuidadora tem disposição intrínseca para auxiliar os outros, e seu papel como cuidadora principal é reconhecido e respeitado pelos outros membros. Ela conta com uma espécie de retaguarda, por ter $\mathbf{G}$ e $\mathbf{E}$ atuando como cuidadores secundários (ainda que a maioria das tarefas recaia em F; Barbosa, Oliveira, \& Figueiredo, 2012; Diogo, Ceolim, \& Cintra, 2005; L. Vieira, Nobre, Bastos, \& Tavares, 2012). A família incentiva a independização do idoso, e $\mathbf{G}$ incentiva I a movimentar-se, auxiliando-o. Sebastião e Albuquerque (2011) consideram que as atitudes da família podem contribuir para aumentar ou diminuir, como neste caso, a dependência do idoso. Entre os indicadores de risco, destaca-se a sobrecarga do microssistema familiar, devido à transferência do cuidado do idoso à família, a partir da Política Nacional do Idoso e da Constituição de 1988 (Areosa \& Areosa, 2008; C. 
P. B. Vieira \& Fialho, 2010). Junto a isso, são indicadores de risco o fato de I estar acamado, fazer uso de muitas medicações, e estar instável emocionalmente. I sente-se um fardo à família por depender de seus cuidados, o que lhe causa angústia (L. Vieira et al., 2012). Ainda, o próprio idoso não participou nem participa dos processos decisórios sobre seu cuidado, algo que o deixa, de certa maneira, apartado da sua própria doença.

F está sobrecarregada, por estarem centradas nela as tarefas de cuidado e de organização da casa, além de ter dois filhos que, em idades diferentes, demandam constante atenção:

Ai, tem dias que é muito cansativo, né. Ainda mais que eu tive bebê e a gente se priva de muita coisa também, né. . . Porque eu fico aqui de segunda a sábado, sábado minha mãe chega sete horas da noite. E quando é domingo . . . a gente sempre tem que levar ele em algum lugar. Pra ele sair um pouco, sabe? Então acaba que a gente fica... a gente se priva das coisas, né?. (F)

Ela sente-se estressada e frustrada, e não percebe aspectos positivos em ser cuidadora. Possivelmente, tais sentimentos têm relação com o fato de ter abandonado o curso superior e o emprego para cuidar do pai, além de não ter apoio social fora do microssistema familiar:

. . sempre gostei de trabalhar, porque pra mim é complicado né, mas claro, eu fico porque é meu pai, porque se não... Não seria essa a minha escolha, de um dia virar cuidadora. Eu gostaria de trabalhar fora, sabe. ... Só pelo fato de eu ter que ter parado com os meus estudos, ter que, né, me centralizar mais neles né, ajudar ele né, a mãe. (F)

Os cuidadores familiares comumente se veem forçados a retirar-se do mercado de trabalho por não conseguir dar conta das duas demandas (Sebastião \& Albuquerque, 2011). Além disso, filha e pai são distantes emocionalmente, e a família como um todo tem dificuldade de prover suporte emocional aos seus membros, o que resulta na centralidade dos seus cuidados nos aspectos clínicos e físicos.

\section{Autopercepção e Positividade}

Em relação à autopercepção e à positividade dos membros, I percebe-se como uma pessoa com capacidade para melhorar, se vê como trabalhador, que gosta de ajudar os outros, o que tem relação com sua perseverança, otimismo e esperança de que sua situação irá melhorar (o que é respeitado pela família). A presença da crença religiosa o auxilia a se manter positivo (Tavares et al., 2012). F percebe-se capaz de dar conta das demandas, apesar do alto nível de estresse, e se diz pacienciosa, características importantes para um cuidador (L. Vieira et al., 2012). Neste sentido, $\mathbf{F}$ procura amenizar o peso emocional, divertindo-se com as situações inusitadas do seu dia. $\mathbf{G}$ e os filhos são motivos de alegria para $\mathbf{F}$.

Destaca-se a presença dos seguintes indicadores de risco: I tem se sentido muito triste, solitário e inútil por estar acamado, como exemplifica o trecho abaixo, o que é comum em situações como esta (Tavares et al., 2012): "Bah, me sinto inútil! Péssimo!" (I). Tavares e colaboradores (2012) citam a dificuldade que a pessoa acamada tem em lidar com a impossibilidade de realizar ações que desempenhava normalmente antes. Ao mesmo tempo em que I crê que possa melhorar um dia, sente-se desanimado frente às dificuldades, à rotina exatamente igual dia após dia, à "falta do que fazer" além de assistir televisão e ficar deitado o dia todo: "É só o que tem pra fazer [chorando]. Não tem outra coisa pra ver ... Fico olhando todo dia" (I).

F aparenta ser "autossuficiente", o que reflete uma atitude da família, e não busca fontes de apoio, apesar dos relatos de sentimentos de estresse, sobrecarga e cansaço. Ainda, F aparenta ter baixa autoestima, dificuldade de perceber e nomear suas características positivas, e não fala sobre as frustrações relacionadas ao seu papel de cuidadora, o que é considerado indicador de risco para ela (L. Vieira et al., 2012).

\section{Relações Intrafamiliares}

Sobre as relações estabelecidas entre os membros, destacam-se como fatores protetivos, para I, o fato de sentir-se bem cuidado pela famí- 
lia, e para $\mathbf{F}$, a presença dos filhos e do marido, que são motivos de alegria. Existe uma relação afetiva entre eles, e percebe-se que o vínculo entre $\mathbf{F}$ e $\mathbf{G}$ foi fortalecido após a situação de dependência. O microssistema familiar percebe-se com capacidade de adaptação e de reorganização, e seus membros sentem-se seguros para tomar decisões importantes quando necessário. A família percebe a situação como administrável, e existe um processo democrático de tomada de decisão entre os cuidadores.

Apesar disso, $\mathbf{F}$ precisa lidar com o envelhecimento do pai em um momento de busca de independência financeira e de formação da sua família, e a própria família precisou reorganizar-se para lidar com o envelhecimento com dependência. A cuidadora e a família redefiniram seus projetos em função da situação de saúde e da necessidade de cuidados de um dos membros da família (Diogo et al., 2005; Sebastião \& Albuquerque, 2011; L. Vieira et al., 2012). Frente a esses sentimentos descritos, evidencia-se o fato de seus membros não costumarem emitir elogios ou exaltarem a capacidade familiar em lidar com essa situação adversa. A família tem dificuldades de expressar e discutir os sentimentos negativos relacionados à condição de cuidado/ cuidador. Além disso, não há a percepção de aspectos positivos na situação de cuidado: " $A i$, não era o que eu queria pra mim né? Mas... Aspecto positivo... Bah... Não sei te responder, assim, na verdade não... porque eu to, eu fico assim porque... porque é só eu né..." (F). Esse dado contraria a literatura, que aponta que é comum a família obter satisfação emocional e perceber um novo sentido para a vida após a situação de cuidado (Sebastião \& Albuquerque, 2011). Diversos estudiosos (Sebastião \& Albuquerque, 2011; L. Vieira et al., 2012) afirmam que a maneira como a família reagirá e as consequências da situação de dependência estão ligadas, entre outros aspectos, à qualidade dos seus laços afetivos. No funcionamento familiar, há uma dificuldade de diferenciação de alguns papéis e díades, pois todos estão sempre juntos, e o respeito às necessidades individuais está enfraquecido, além de haver muitos segredos familiares. A família está centrada no idoso, e outros problemas gerais e individuais parecem ficar subdimensionados ou subestimados.

\section{Considerações Finais}

A partir da análise realizada, conclui-se que a família lida com a situação do idoso acamado centrando-se no cuidado físico deste. As necessidades e desejos de $\mathbf{F}$ tornaram-se invisíveis e ela não dispõe de rede de apoio extrafamiliar. Embora seja comum em casos semelhantes a falta de apoio social, pontua-se sobre a importância do cuidado com o cuidador. É importante lembrar a sobrecarga e o alto nível de estresse ocasionado pela função. É interessante que as equipes de saúde que acompanham idosos acamados possam manter um olhar atento também para o cuidador, bem como auxiliar a família na busca de outros recursos. Além disso, merece atenção a sensação de invalidez que o idoso relata, o que lhe causa frustração; ambos, cuidadora e idoso, poderiam diminuir sua sobrecarga com a existência de atividades de trabalho e lazer alternativas e adaptadas para esta realidade. Ações intersetoriais e de parceria entre a equipe de saúde, a família e outros dispositivos da rede de atenção local, como grupos ou associações de apoio, também poderiam desempenhar uma função de promoção de saúde individual e familiar.

Apesar de apresentar mais fatores de risco do que de proteção, pode-se perceber que a família encontra-se em um processo adaptativo positivo desde a ocorrência dos AVCs, mostrando-se organizada, dentro do possível, e orientada aos cuidados com I, ainda que estejam centrados nos aspectos clínicos. I sente-se cuidado nessa família. Portanto, esta é uma família que se encontra em processo de resiliência frente à situação de envelhecimento com dependência.

Apesar da dificuldade de generalização dos resultados encontrados no presente estudo, por ser um caso único, percebe-se que os fatores de risco e de proteção encontrados podem ser comuns, reservadas as devidas particularidades, a outras famílias que vivenciam a mesma situação. Destaca-se, no presente estudo, a inclusão e o coprotagonismo do idoso e da cuidadora na colocação de suas falas e sentimentos, algo ainda 
novo nesta área, já que, normalmente, investiga-se somente o universo do cuidador.

Sugerem-se, portanto, novos estudos com mais famílias, a fim de investigar se os elementos da dinâmica familiar encontrados neste estudo, os quais foram apresentados mais aprofundadamente devido à própria característica do método, também se fazem presentes em outros microssistemas familiares. Aponta-se, por fim, a contribuição do presente artigo para a consolidação da TBDH como método de análise e compreensão deste fenômeno.

\section{Referências}

Areosa, S. V. C., \& Areosa, A. L. (2008). Envelhecimento e dependência: Desafios a serem enfrentados. Textos e Contextos, 7(1), 138-150.

Augusto, F. M. F., da Silva, I. P., \& Ventura, M. M. (2009). Filhos cuidadores: Escolha, mudanças e desafios. Revista Kairós Gerontologia, 12(2), 103-118.

Baptista, M. N. (2007). Inventário de Percepção de Suporte Familiar (IPSF): Estudo componencial em duas configurações. Psicologia: Ciência e Profissão, 27(3), 496-509. doi:10.1590/S141498932007000300010

Barbosa, A. L., Oliveira, A. L., \& Figueiredo, D. (2012). Rede informal de apoio à pessoa idosa dependente: Motivações e fatores de stress em cuidadores primários e secundários. Revista Kairós Gerontologia, 15(1), 11-29.

Bronfenbrenner, U. (1996). A ecologia do desenvolvimento humano: Experimentos naturais e planejados. Porto Alegre, RS: Artes Médicas. (Original publicado em 1979)

Bronfenbrenner, U. (2011). Bioecologia do desenvolvimento humano: Tornando os seres humanos mais humanos. Porto Alegre, RS: Artmed.

Caldas, C. P. (2003). Envelhecimento com dependência: Responsabilidades e demandas da família. Cadernos de Saúde Pública, 19(3), 773-781. doi:10.1590/S0102-311X2003000300009

Cassol, L., \& De Antoni, C. (2011). Família e abrigo como rede de apoio social e afetiva. In D. D. Dell'Aglio, S. H. Koller, \& M. A. M. Yunes (Eds.), Resiliência e Psicologia Positiva: Interfaces do risco à proteção (pp. 173-201). São Paulo, SP: Casa do Psicólogo.
Cecconello, A. M. (2003). Resiliência e vulnerabilidade em famílias em situação de risco (Tese de doutorado, Curso de Pós-Graduação em Psicologia do Desenvolvimento, Universidade Federal do Rio Grande do Sul, Porto Alegre, RS, Brasil). Recuperada em http://biblioteca.esec.pt/cdi/ ebooks/docs/Cecconello_resiliencai.pdf

Cruz, D. C. M., Loureiro, H. A. M., Fernandes, M. M., \& Silva, M. A. N. (2010). As vivências do cuidador informal do idoso dependente. Revista Enfermagem Referência, 3(2), 127-136.

De Antoni, C., Barone, L., \& Koller, S. H. (2011). Violência e pobreza: Um estudo sobre vulnerabilidade e resiliência familiar. In D. D. Dell'Aglio, S. H. Koller, \& M. A. M. Yunes (Eds.), Resiliência e Psicologia Positiva: Interfaces do risco à proteção (pp. 141-171). São Paulo, SP: Casa do Psicólogo.

De Antoni, C., \& Koller, S. H. (2010). Uma família fisicamente violenta: Uma visão pela teoria bioecológica do desenvolvimento humano. Temas em Psicologia, 18(1), 17-30.

Diogo, M. J. D., Ceolim, M. F., \& Cintra, F. A. (2005). Orientações para idosas que cuidam de idosos no domicílio. Revista da Escola de Enfermagem da USP, 39(1), 97-102. doi:10.1590/ S0080-62342005000100013

Féres-Carneiro, T. (1997). Entrevista Familiar Estruturada - EFE: Um método de avaliação das relações familiares. Temas em Psicologia, 5(3), 63-94.

Instituto Brasileiro de Geografia e Estatística. (2011). Resultados do Censo 2010. Brasília, DF: Autor. Recuperado em http://www.censo2010.ibge. gov.br/

Karsch, U. M. (2003). Idosos dependentes: Famílias e cuidadores. Cadernos de Saúde Pública, 19(3), 861-866. doi:10.1590/S0102-311 X2003000300019

Koller, S. H., \& De Antoni, C. (2004). Violência familiar: Uma visão ecológica. In S. H. Koller (Ed.), Ecologia do desenvolvimento humano: Pesquisa e intervenção no Brasil (pp. 293-310). São Paulo, SP: Casa do Psicólogo.

Lavinsky, A. E., \& Vieira, T. T. (2004). Processo de cuidar de idosos com acidente vascular encefálico: Sentimentos dos familiares envolvidos. Acta Scientiarum. Health Sciences, 26(1), 41-45. doi:10.4025/actascihealthsci.v26i1.1614 
Mazza, M. M. P. R., \& Lefévre, F. (2005). Cuidar em família: Análise da representação social da relação do cuidador familiar com o idoso. Revista Brasileira de Crescimento e Desenvolvimento Humano, 15(1), 1-10.

Morais, N. A., \& Koller, S. H. (2004). Abordagem ecológica do desenvolvimento humano, Psicologia Positiva e resiliência: Ênfase na saúde. In S. H. Koller (Ed.), Ecologia do desenvolvimento humano: Pesquisa e intervenção no Brasil (pp. 91-108). São Paulo, SP: Casa do Psicólogo.

Moreira, M. D., \& Caldas, C. C. (2007). A importância do cuidador no contexto da saúde do idoso. Escola Anna Nery Revista de Enfermagem, 11(3), 520-525. doi:10.1590/S141481452007000300019

Nardi, E. F. R., \& Oliveira, M. L. F. (2008). Conhecendo o apoio social ao cuidador familiar do idoso dependente. Revista Gaúcha de Enfermagem, 29(1), 47-53.

Pereira, R. A., Santos, E. B., Fhon, J. R. S., Marques, S., \& Rodrigues, R. A. P. (2013). Sobrecarga dos cuidadores de idosos com acidente vascular cerebral. Revista da Escola de Enfermagem da USP, 47(1), 185-192. doi:10.1590/S008062342013000100023

Poletto, M., \& Koller, S. H. (2011). Resiliência: Uma perspectiva conceitual e histórica. In D. D. Dell'Aglio, S. H. Koller, \& M. A. M. Yunes (Eds.), Resiliência e Psicologia Positiva: Interfaces do risco à proteção. (pp. 19-44). São Paulo, SP: Casa do Psicólogo.

Sebastião, C., \& Albuquerque, C. (2011). Envelhecimento e dependência. Estudo sobre os impactes da dependência de um membro idoso na família e no cuidador principal. Revista Kairós Gerontologia, 14(4), 25-49.

Silva, M. R. S., Lacharité, C., Silva, P. A., Lunardi, V. L., \& Lunardi, W. D., Filho. (2009) Processos que sustentam a resiliência familiar: Um estudo de caso. Texto \& Contexto Enfermagem, 18(1), 92-99.

Silveira, T. M., Caldas, C. P., \& Féres-Carneiro, T. (2006). Cuidando de idosos altamente dependentes na comunidade: Um estudo sobre cuidadores familiares principais. Cadernos de Saúde Pública, 22(8), 1629-1638. doi:10.1590/S0102$-311 \mathrm{X} 2006000800011$
Tavares, K. O., Scalco, J. C., Vieira, L., Silva, J. R., \& Bastos, C. C. C. B. (2012). Envelhecer, adoecer e tornar-se dependente: A visão do idoso. Revista Kairós Gerontologia, 15(3), 105-118.

Teodoro, M. (2012). Alguns instrumentos para avaliação familiar no Brasil. In M. Teodoro \& M. N. Baptista (Eds.), Psicologia de família: Teoria, avaliação e intervenção (pp. 168-175). Porto Alegre, RS: Artmed.

Thober, E., Creutzberg, M., \& Viegas, K. (2005). Nível de dependência de idosos e cuidados no âmbito domiciliar. Revista Brasileira de Enfermagem, 58(4), 438-443. doi:10.1590/S003471672005000400011

Tier, C. C., Souza, M. B., Soares, M. C. F., Santos, S. S. C., Baisch, A. L. M., \& Cestari, M. A. C. (2006). Política de saúde do idoso: Iniciativas identificadas no município de Rio Grande-RS. Cogitare Enfermagem, 11(1), 39-43.

Vieira, C. P. B., \& Fialho, A. V. M. (2010). Perfil de cuidadores familiares de idosos com acidente vascular cerebral isquêmico. Revista RENE, 11(2), 161-169.

Vieira, L., Nobre, J. R. S., Bastos, C. C. B. C., \& Tavares, K. O. (2012). Cuidar de um familiar idoso dependente no domicílio: Reflexões para os profissionais da saúde. Revista Brasileira de Geriatria e Gerontologia, 15(2), 255-264. doi:10.1590/S1809-98232012000200008

Walsh, F. (1998). Strengthening family resilience. New York: The Guilford Press.

Willig, M. H., Lenardt, M. H., \& Méier, M. J. (2012). A trajetória das políticas públicas do idoso no Brasil: Breve análise. Cogitare Enfermagem, 17(3), 574-577. doi:10.5380/ce.v17i3.29298
Recebido: 18/03/2014

$1^{a}$ revisão: $17 / 06 / 2014$ Aceite final: 17/06/2014 